\title{
An alternate novel approach to classify lip prints
}

Jagmeet Kaur and Mukesh Kumar Thakar*

\begin{abstract}
Background: The wrinkles and grooves present on the sulci labiorum of human lips form characteristic patterns. As previous authors claimed, these can be used for personal identification in forensic cases because they are unique, permanent, and classifiable. Many scientists had devised different systems to classify the lip prints (Suzuki and Tsuchihashi, Martin Santos, Renaud, Afchar Bayar, and Jose Maria Dominguez). These systems were based solely on the shape of patterns present on the whole lip. However, sometimes, lip prints affected by either habitual smoking or any other pathological conditions are encountered. The investigator may have to form an opinion on partial lip print to identify the culprit. Therefore, in the present study, an alternative comprehensive system to classify even the partial prints has been proposed. Lip print samples were collected from 500 individuals (400 females and 100 males, respectively) using the tape lifting method. The whole lip print (Klein's zone) was divided into 10 quadrants (five each on upper and lower lips) to study the whole pattern area thoroughly. The sample-wise and quadrant-wise frequency of all the patterns was statistically calculated. Sexual dimorphism of the lip print patterns was also assessed statistically.

Results: The method used emphasizes the consistency of patterns, which have been divided into Basic and Combination Patterns. Detailed examination of lip prints revealed that all the quadrants tend to have 7 types of Basic Patterns and 43 types of Combination Patterns despite similar appearance. These patterns can be further categorized into various subtypes based on the direction and orientation of wrinkle lines constituting the original pattern. Most of the Basic and Combination Patterns were widely distributed in all the analysed lip print samples and showed significant dependence on the sex of the subject.
\end{abstract}

Conclusions: The lip print patterns examined in the present study can be useful as an alternative to the existing systems to classify even partial lip marks recovered at the crime scene.

Keywords: Forensic science, Cheiloscopy, Klein's zone, Lip prints, Patterns, Classification

\section{Background}

For ages, crime investigations have been undertaken manually and were primarily dependent upon the witnesses. The primary mode of criminal enquiries relied upon 3rd-degree methods or, to a limited extent, on the interpretation of evidence (like footprint analysis by Khojis of Rajasthan, India). The current investigation scenario has shown a remarkable transformation from manual to scientific investigations; that is, the modern crime scene

*Correspondence: mukeshk38@gmail.com

Department of Forensic Science, Punjabi University, Patiala, Punjab 147002, India evaluation depends on observing and explicating the physical evidence and subsequent analysis in the forensic labs through scientific techniques. Personal identification has played a crucial role in linking the suspect with the scene of crime and victim. Moreover, it has relevance in spotting the unknown deceased persons in homicidal, suicidal and accidental cases (Rastogi and Parida 2012). Since the last few centuries, fingerprints (because of their permanence and uniqueness) have been the only significant means of human identification. However, increased awareness regarding the advanced scientific techniques to commit a crime and crime detection procedures has evoked the criminals to take precautions like wearing 
hand gloves to avoid or hide their fingertips while committing the malicious act (Cummins and Midlo 1961). A conviction based on fingerprint evidence often fails when such circumstances arrive. Thus, the investigating officer has to rely upon alternative techniques like Cheiloscopy as corroborative evidence (Prabhu et al. 2010).

The asymmetrical lines present on the lips form a typical pattern on the sulci labiorum, considered individualistic as fingerprints. The wrinkles and grooves present on labial mucosa (called sulci labiorum) give rise to a characteristic pattern. The study of lips and lip prints is referred to as Cheiloscopy (Prabhu et al. 2010; Sivapathasundharam et al. 2001; Sekharan 2011). The importance of cheiloscopy can be linked to its ability to distinguish individuals based on the shape of wrinkles and grooves (Suzuki and Tsuchihashi 1971; Fonseca et al. 2019). Authors have claimed that lip print patterns are remarkably stable and do not change during a person's life (Sivapathasundharam et al. 2001). It has also been verified that lip print patterns recover themselves even after undergoing severe alterations such as trauma, inflammation, and diseases, such as herpes (Castello et al. 2005). The disposition and the form of furrows do not vary with changing environmental factors (Sivapathasundharam et al. 2001; Hirth et al. 1975). Lip print patterns get inherited over generations of families and can be used to trace familial lineage (George et al. 2016; Mala et al. 2017; Loganadan et al. 2019).

Lip prints patterns are also classifiable. Various systems to classify lip prints have been formerly given by eminent scientists like Suzuki and Tsuchihashi (1971), Martin Santos (1967), Renaud (1973), Caldas et al. (2007), and Jose Maria Dominguez (Caldas et al. 2007) based on various types of wrinkles and grooves, whereas Kasprzak (2000) classified lip prints on the basis of individual characteristics. Among all the systems mentioned above, the Suzuki and Tsuchihashi system of lip print classification (1970) has been the most widely used (Fonseca et al. 2019).

The classification systems of lip prints devised to date were based on the general shape of wrinkles and grooves present on the lips. However, the present study aimed to differentiate lip prints based on the inclination, orientation, numerical superiority, and co-existence of diverse forms of lip print prototypes. An attempt has been made to formulate an alternative and comprehensive system to classify the lip prints. Moreover, in this study, Klein's zone has been divided into 10 quadrants (five on the upper lip and the remaining five on the lower lip) to analyse every part of the lip thoroughly. This approach is expected to identify a person conclusively, even if a small area of lips is affected by smoking or tobacco chewing or any pathological condition or a fragmented or partial print encountered at the crime scene. Emphasis has been laid to confirm whether the lip print pattern present in every quadrant shows any dissimilarity and to check whether each pattern exists singly or as a combination of various forms.

\section{Methods}

The materials used to complete the present study included lipstick (23 M matte; Colorbar, USA), hypoallergenic lip balm (Himalaya, India), transparent tape, scissors, white bond paper (Spectra ${ }^{\circledR}$; Trident Group ${ }^{\text {TM }}$, India), face tissues (Origami, India), deep pore cleansing milk (Ayur Herbals, India) and magnifying glass, etc. The lip print samples were collected from 500 individuals (400 females and 100 males) of varying ages (above 18 years), randomly chosen from various university departments. All the participants were Indian citizens belonging to different areas of the Punjab region. The standardized tape lifting method was adopted for collecting samples, since it is the most widely used method for taking lip prints (Prabhu et al. 2010; Fonseca et al. 2019). At least three prints were taken from each individual. During the collection of prints, every person was briefed about the study and written consent was obtained. Prior to sampling, apposite permission was obtained from the Institutional Ethics Committee (Reference Number: IEC 2017/06 dated 20-01-2017) to carry out the present research. Persons below 18 years of age, persons with known hypersensitivity to cosmetics and persons having abnormalities or pathological conditions on lips were excluded from the study. Individuals having a habit of smoking, tobacco chewing, and drug addiction were also not included in the present study.

Firstly, the subject's lips were gently cleaned with soft facial tissue for collecting the prints. Subjects having dry lips were asked to moisten their lips with a lip balm. After that, a fine layer of lipstick was applied to the subject's lips appropriately. The lipstick was allowed to dry for 1-2 min. A transparent lifting tape was then slowly and firmly fixed onto the subject's lips (the adhesive side of tape sticking to the lips), while minimal pressure was applied with the index finger. The tape was removed quickly and carefully from the subject's lips, which was then fixed onto white bond paper. The impressions were photographed with a 12-megapixel iPhone 8 camera. Close-up photos were taken by placing two metric conversion cards (National Institute of Standards and Technology, Gaithersburg) adjacent to each other. The digital images were systematically numbered and saved in .jpeg format. The images were enhanced using Paint (MS Paint 2007) software and Picasa Photo Viewer (Picasa 3) software. Each upper and lower lip print was divided into 10 quadrants, as shown in Fig. 1. The nomenclature 


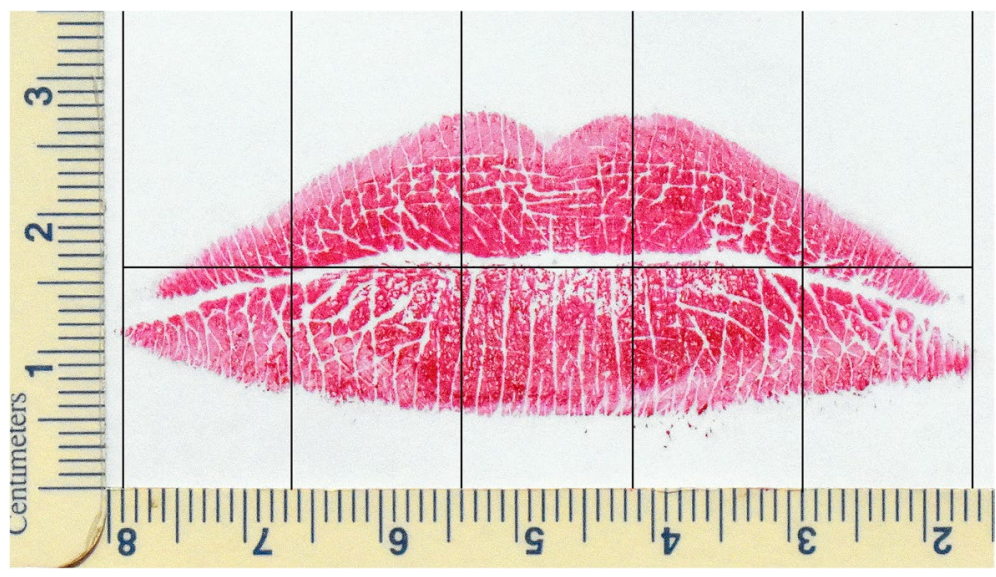

Fig. 1 Image showing the division of a lip print sample into ten quadrants. Quadrants from top-left to right: ULR, UMR, UC, UML, ULL; Bottom-left to right: LLR, LMR, LC, LML, LLL

and abbreviations assigned to the quadrants are given in Table 1.

Each quadrant was carefully accessed and profoundly studied. After that, the Pattern types observed in each quadrant were divided into Basic Patterns and Combination or Miscellaneous Patterns based on the shape, direction of inclination, orientation and numerical superiority of the wrinkle or line formations. The patterns present individually in each quadrant, having only one type of wrinkles or lines, were classified as Basic Patterns (Table 2). In contrast, the patterns where more than one type of wrinkles or lines were present were termed Combination Patterns (Table 3). In other words, a Combination Pattern consisted of two or more Basic patterns. The nomenclature of Basic Patterns was formalized based on the pattern's generalized shape and appearance. However, the nomenclature of Combination Patterns was based on the numerical superiority

Table 1 The nomenclature and abbreviations assigned to the quadrants into which lips were divided

\begin{tabular}{lll}
\hline S. no. & Name of quadrant & $\begin{array}{l}\text { Abbreviation } \\
\text { used }\end{array}$ \\
\hline 1 & Upper lateral right & $\mathrm{UL}_{R}$ \\
2 & Upper middle right & $\mathrm{UM}_{R}$ \\
3 & Upper central & $\mathrm{UC}$ \\
4 & Upper middle left & $\mathrm{UM}_{\mathrm{L}}$ \\
5 & Upper lateral left & $\mathrm{UL}_{\mathrm{L}}$ \\
6 & Lower lateral right & $\mathrm{LL}_{R}$ \\
7 & Lower middle right & $\mathrm{LM}_{R}$ \\
8 & Lower central & $\mathrm{LC}$ \\
9 & Lower middle left & $\mathrm{LM}_{\mathrm{L}}$ \\
10 & Lower lateral left & $\mathrm{LL}_{\mathrm{L}}$ \\
\hline
\end{tabular}

of the Basic Patterns constituting the Combination Pattern. The Basic Pattern covering a major portion of the Combination Pattern was written as the primary pattern followed by the other basic pattern covering the lesser or minor portion. For example, if the combination pattern consisted of Lines and Bifurcations and the total number of bifurcations outnumbered the lines, the final pattern was designated as Bifurcations + Lines.

The patterns (Basic and Combination), which were commonly present and repeated throughout the sample size (500 samples and 5000 quadrants), were grouped into Tables 2 and 3. Macro photographs of every pattern (Basic and Combination) were prepared by enhancing the close-up photographs of lip print samples. The digital copies of the original photographs were cropped by using MS Office Paint, and the selected portions were enlarged (by using Microsoft Office Picture Manager) up to the extent to produce clear macro photographs.

Sample-wise frequency and quadrant-wise frequency were calculated for every Basic and Combination pattern using SPSS 17.0 software and are given in Tables 4 and 5. The corresponding findings have been briefed in Figs. 2 and 3. Gender-based frequency of various Basic and Combination Patterns was also calculated to determine the predominance of various Basic and Combination Patterns. The sample-wise frequency and quadrant-wise frequency of all the patterns for 100 female and 100 male lip print samples have been given in Tables 6, 7, 8, and 9. Chi-square test of independence was applied to determine the dependence of occurrence of Basic and Combination Patterns (separately) on the sex of the sample contributor. The significance level was taken as $\alpha=0.05$ using the formula: $\chi^{2}=\sum \frac{(O-E)^{2}}{\mathrm{E}}$, 
Table 2 Various types of Basic Patterns and their subtypes along with macro photographs

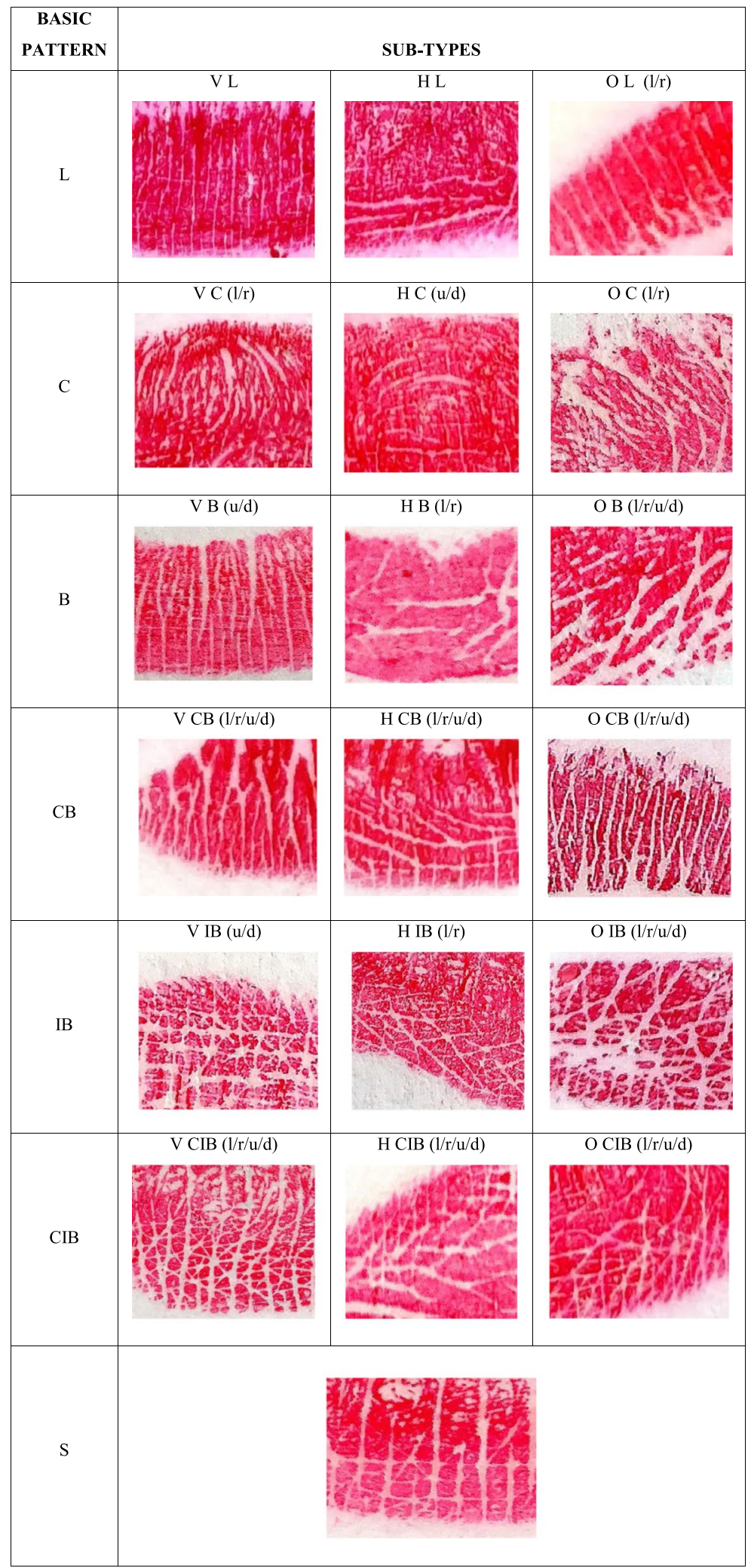

$L$, lines; $C$, curves; $B$, bifurcations; $C B$, curved bifurcations; $I B$, intersected bifurcations; $C I B$, curved intersected bifurcations; $S$, squares; $V$, vertical; $H$, horizontal; $O$, oblique; I, left; $r$, right; $u$, upward; $d$, downward 
where $O$ is the observed value, and $E$ is the expected value of frequency of occurrence of novel features in male and female samples, and the Null Hypothesis, H0: Frequency of pattern is independent of the sex of the sample.

Blind trials were conducted on some lip print samples to validate the current study's findings.

\section{Results}

\section{Classification of patterns}

The study was conducted to suggest and formulate an alternative approach to classify the lip prints. The pattern of wrinkles and grooves present in the lip impressions was analysed precisely by dividing the lip impression into ten areas or quadrants. Patterns present in 500 lip print samples and their subsequent 5000 quadrants were analysed thoroughly to determine various pattern types which existed either singly or as a blend of different types of patterns. After analysis, seven types of Basic Patterns of wrinkles and grooves were found to be present in the lip impressions of the males as well as females, described as follows:

Lines: The wrinkles and grooves running unidirectional across the lip prints forming a pattern, but lacking any curvature and not splitting further, were named as Lines (Table 2).

Curves: The wrinkles and grooves running unidirectional across the lip prints, having a curvature, but not splitting further were named as Curves (Table 2).

Bifurcations: The wrinkles and grooves running unidirectional across the lip prints, lacking any curvature, and splitting further into two divisions (inclined in the opposite directions to each other) were named as Bifurcations (Table 2).

Curved Bifurcations: The wrinkles and grooves running unidirectional across the lip prints at an angle of curvature and splitting further into two divisions (inclined in the opposite directions to each other) were named as Curved Bifurcations (Table 2).

Intersected Bifurcations: The wrinkles and grooves running unidirectional or bidirectional across the lip prints, lacking any curvature, splitting further into two divisions (inclined in the opposite directions to each other) and merging into each other, were named as Intersected Bifurcations (Table 2).

Curved Intersected Bifurcations: The wrinkles and grooves running unidirectional or bidirectional across the lip prints at an angle of curvature and splitting further into two divisions (inclined in the opposite directions to each other) as well as merging into each other were named as Curved Intersected Bifurcations (Table 2).

Squares: The wrinkles and grooves running bidirectional across the lip prints, crossing each other at a right angle without any curvature, and not splitting any further were named as Squares (Table 2).

These aforesaid Basic Patterns were further divided into various subtypes based on the direction and angularity of the lines forming the patterns (Table 2). Various types of Basic Patterns and their respective subtypes, along with their macro photographs, have been given in Table 2. Out of the seven Basic Patterns (as shown in Table 2), six patterns (viz. Lines, Curves, Bifurcations, Curved Bifurcations, Intersected Bifurcations, and Curved Intersected Bifurcations) ought to be divided into three subtypes (Vertical, Horizontal, and Oblique), which in turn gave rise to 18 varieties of Basic Patterns (Table 2). All the subtypes of Basic Patterns of lip prints could be further differentiated into diverse sub-sub types like left, right, upward, and downward depending upon the inclination and orientation of wrinkles or lines which form the lip print patterns. However, the Squares could not be divided into any subtypes.

Similarly, various types of Combination Patterns and their respective subtypes, along with their macro photographs, have been given in Table 3. It is evident from Table 3 that two or more types or subtypes of Basic Patterns could be present together in a lip print area to give rise to another pattern as a whole, which makes a Combination Pattern. Accordingly, 43 different types of Combination Patterns have been assorted. These patterns could be further differentiated into various forms or subtypes, depending upon the subtypes of Basic Patterns constituting the Combination Pattern. Statistically, the amalgamation of 7 varieties of Basic patterns gave rise to 43 different appearances of Combination Patterns.

The patterns that could not be classified and categorized as either Basic or Combination patterns were designated as Miscellaneous patterns.

\section{Validation of distribution of basic and combination patterns}

In order to validate the distribution of Basic and Combination Patterns, 500 lip print samples were statistically analysed to calculate the frequency, and the corresponding values have been given in Tables 4 and 5 . As in the present study, the whole lip print was divided into 10 parts or quadrants, all the quadrants (5000) were also analysed thoroughly to study the frequency of Basic and Combination Patterns in each quadrant. Similarly, the percentage frequency of these patterns was statistically calculated, which is numerically summarized in Tables 4 and 5 .

Table 4 and Fig. 2 show the frequency of Basic Patterns in lip print samples (whole lip) and their subsequent quadrants. It is evident from Table 4 (Fig. 2) that 
Table 3 Various types of Combination Patterns and their subtypes along with macro photographs
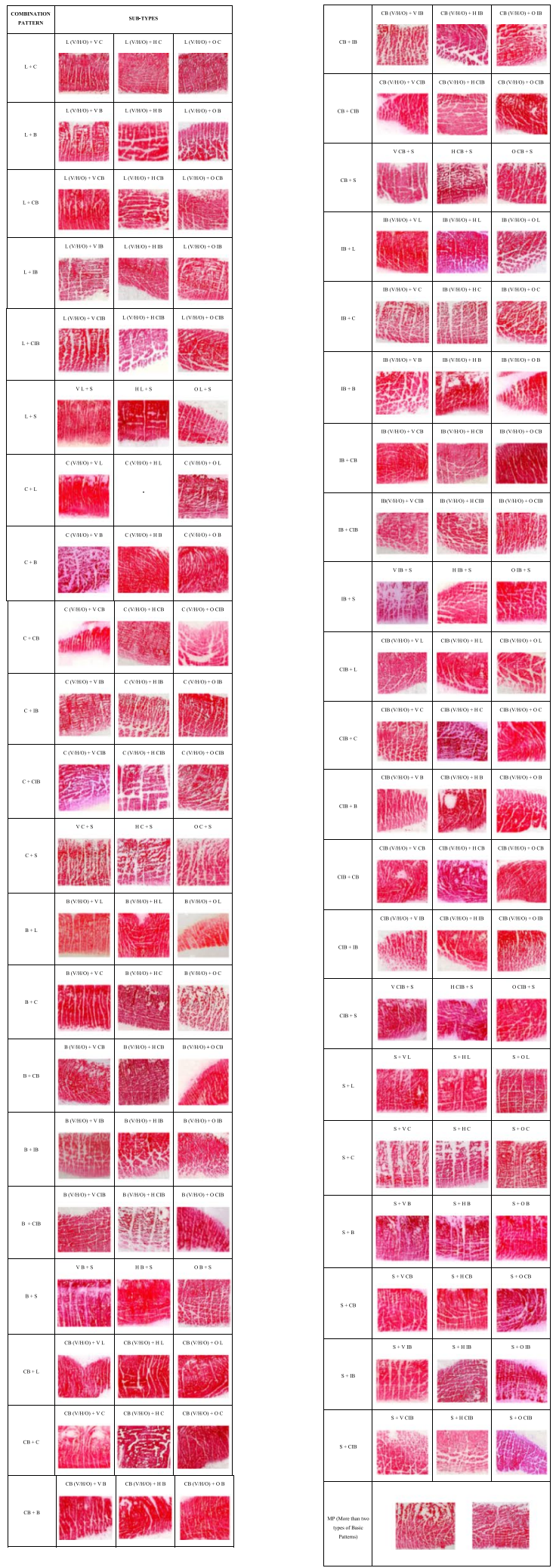

$L$, lines; $C$, curves; $B$, bifurcations; $C B$, curved bifurcations; $I B$, intersected bifurcations: $C I B$, curved intersected bifurcations; $S$, squares; $M P$, miscellaneous pattern
Lines (Basic Pattern) were found to be present in 3.60\% samples and $0.38 \%$ quadrants. Curves and Bifurcations repeated themselves (frequency) in $1.00 \%$ and $37.00 \%$ samples; and in $0.10 \%$ and $6.12 \%$ quadrants, respectively. Similarly, Curved Bifurcations, Intersected Bifurcations, and Curved Intersected Bifurcations were found to be distributed (frequency) in $38.00 \%$ samples; $7.92 \%$ quadrants, $54.60 \%$ samples; $11.46 \%$ quadrants and $63.60 \%$ samples; $14.64 \%$ quadrants, respectively. Also, the Squares were present in $4.20 \%$ samples and $0.50 \%$ quadrants.

Similarly, Table 5 and Fig. 3 represent the frequency of Combination Patterns (43) in the whole lip print samples and their subsequent quadrants. It is evident from Table 5 (Fig. 3) that among Lines (major pattern) and their combinations with other Basic Patterns (6), the pattern Lines + Bifurcations was found to have the maximum frequency, i.e. $9.40 \%$ (sample-wise) and 1.02\% (quadrant-wise), followed by Lines + Squares (present in $7.00 \%$ samples and $0.72 \%$ quadrants). Simultaneously, the pattern Lines + Curves was found to have the minimum frequency of distribution $(0.60 \%$ in samples and $0.06 \%$ in quadrants).

Among various Combination Patterns of Curves (6), the pattern Curves + Curved Bifurcations was found to possess maximum frequency, viz. in $1.00 \%$ samples and $0.12 \%$ quadrants; while Curves + Lines were found to have minimum distribution (in $0.40 \%$ samples and $0.04 \%$ quadrants). Maximum sample-wise, as well as quadrantwise distribution frequencies of various Combination Patterns of Bifurcations (major pattern), was found to be $31 \%$ (sample-wise) for Bifurcations + Squares and 4.62\% (quadrant-wise) for Bifurcations + Curved Bifurcations, respectively. Similarly, minimum distribution frequencies of various Combination Patterns of Bifurcations were held by Bifurcations + Curves, i.e. 1.20\% (sample-wise) and $0.12 \%$ (quadrant-wise), respectively.

Among the Combination Patterns embodying Curved Bifurcations as the major pattern (6), Curved Bifurcations + Squares were found to be distributed in $36.20 \%$ samples and $5.58 \%$ quadrants (maximum frequency); while Curved Bifurcations + Curves were found to be minimally distributed in $2.00 \%$ samples and $0.20 \%$ quadrants, respectively. Similarly, considering the patterns presenting Intersected Bifurcations as the major pattern (6), Intersected Bifurcations + Squares were found to possess the maximum distribution frequency, viz. 33.00\% (sample-wise) and 5.54\% (quadrant-wise), while Intersected Bifurcations + Curves showed minimum distribution, i.e. in $1.20 \%$ samples and $0.12 \%$ quadrants. The maximum, as well as minimum sample-wise and quadrant-wise distribution frequencies of various Combination Patterns of Curved Intersected Bifurcations (6), were observed in Curved Intersected Bifurcations + Squares 
Table 4 Frequency of Basic Patterns

\begin{tabular}{llllllll}
\hline Sr. no. & $\begin{array}{l}\text { Type of } \\
\text { Basic } \\
\text { Pattern }\end{array}$ & $\begin{array}{l}\text { Total number of } \\
\text { samples analysed }\end{array}$ & $\begin{array}{l}\text { Number of } \\
\text { samples exhibiting } \\
\text { the pattern }\end{array}$ & $\begin{array}{l}\text { Total number } \\
\text { of quadrants } \\
\text { analysed }\end{array}$ & $\begin{array}{l}\text { Number of } \\
\text { quadrants } \\
\text { exhibiting the } \\
\text { pattern }\end{array}$ & $\begin{array}{l}\text { Sample-wise } \\
\text { percentage } \\
\text { distribution }\end{array}$ & $\begin{array}{l}\text { Quadrant-wise } \\
\text { percentage } \\
\text { distribution }\end{array}$ \\
\hline 1 & L & 500 & 18 & 5000 & 19 & $3.60 \%$ & $0.38 \%$ \\
2 & C & 500 & 05 & 5000 & 05 & $1.00 \%$ & $0.10 \%$ \\
3 & B & 500 & 185 & 5000 & 306 & $37.00 \%$ & $6.12 \%$ \\
4 & CB & 500 & 190 & 5000 & 396 & $38.00 \%$ & $7.92 \%$ \\
5 & IB & 500 & 273 & 5000 & 573 & $54.60 \%$ & $11.46 \%$ \\
6 & CIB & 500 & 318 & 5000 & 732 & $63.60 \%$ & $14.64 \%$ \\
7 & S & 500 & 21 & 5000 & 25 & $4.20 \%$ & $0.50 \%$
\end{tabular}

$L$, lines; $C$, curves; $B$, bifurcations; $C B$, curved Bifurcations; IB, intersected bifurcations; $C I B$, curved intersected bifurcations; $S$, squares

(in 25.80\% samples and 3.84\% quadrants) and Curved Intersected Bifurcations + Curves (in 0.60\% samples and $0.06 \%$ quadrants). In the case of Squares as the major pattern (6), the combination Squares + Bifurcations was extremely distributed in $28.00 \%$ samples and $3.98 \%$ quadrants. Also, Squares + Curves were scarcely present in $0.80 \%$ samples and $0.08 \%$ quadrants. Meanwhile, the Miscellaneous Pattern was fairly distributed in $33.60 \%$ samples and $4.94 \%$ quadrants.

\section{Gender-based frequency of basic and combination patterns}

The gender-based frequency estimation of various Basic patterns revealed that some lip print patterns were predominantly present in the female subjects, while others were more frequently present in the males. It is evident from Tables 6 and 7 that the 'CIB' Basic pattern was predominant in female samples. On the contrary, the ' $\mathrm{B}$ ' and 'CIB' patterns were equally dominant in the male samples. The ' $\mathrm{L}$ ' and ' $\mathrm{C}$ ' patterns were least present in the female samples. Likewise, the ' $\mathrm{S}$ ' pattern was least dominant in the male lip print samples. Also, the ' $\mathrm{C}$ ' basic lip print pattern was not observed in any of the present study's male subjects.

The frequency analysis of various Combination patterns of female and male lip print samples (Tables 8 and 9) revealed that the 'Miscellaneous Pattern (MP-57\%; $8.9 \%$ )' predominates in female lip prints followed by the patterns ' $\mathrm{IB}+\mathrm{CB}$ ' and ' $\mathrm{S}+\mathrm{B}$ '. However, the ' $\mathrm{B}+\mathrm{CB}$ ' pattern was predominantly found $(65 \% ; 11.8 \%)$ in the male lip prints followed by $\mathrm{CB}+\mathrm{B}$ ' and 'MP' patterns. The least common Combination patterns found in the female samples were ' $\mathrm{L}+\mathrm{C}$, ' $\mathrm{L}+\mathrm{CIB}$, ' $\mathrm{C}+\mathrm{L}$, ' $\mathrm{C}+\mathrm{B}$, ' $\mathrm{C}+\mathrm{IB}$, ' $\mathrm{C}+\mathrm{CIB}$, ' $\mathrm{C}+\mathrm{S}$, ' $\mathrm{CB}+\mathrm{C}$, ' $\mathrm{IB}+\mathrm{C}$, ' $\mathrm{CIB}+\mathrm{C}$ ', and 'S $+\mathrm{C}$ ' with only $1 \%$ chances of occurrence in a group of 100 samples. On the contrary, the least commonly occurring Combination patterns in the male samples were ' $\mathrm{C}+\mathrm{L}$ ', ' $\mathrm{B}+\mathrm{C}$,' ' $\mathrm{S}+\mathrm{L}$ ', and ' $\mathrm{S}+\mathrm{C}$ ' with $\%$ frequency (each). Likewise, the patterns ' $\mathrm{L}+\mathrm{C}$ ', ' $\mathrm{L}+\mathrm{IB}$ ', 'C $+\mathrm{B}$, ' $\mathrm{C}+\mathrm{IB}$ ', 'C $+\mathrm{CIB}$ ', $\mathrm{IB}+\mathrm{L}$ ', and ' $\mathrm{CIB}+\mathrm{C}$ ' were not observed in any of the male lip print samples analysed in the present study.

From the chi-square test of independence for Basic patterns, $\chi 2$ came out to be 20.31991 . This calculated value of $\chi 2$ was greater than the critical value (9.49) at $\alpha=0.05$ and $D_{\mathrm{f}}=4$ [Degree of freedom $=(r-1)(c-1)$ ]. Hence, the null hypothesis was rejected. It showed that the Basic pattern is dependent on the sex of the sample contributor. Similarly, for the Combination patterns, the $\chi 2$ came out to be 269.0968 . This calculated value was greater than the critical value (40.113) at $\alpha=0.05$ and $D_{\mathrm{f}}=26$ [Degree of freedom $=(r-1)(c-1)]$. Thus, the null hypothesis was rejected in the case of Combination patterns. Therefore, the statistical analysis of the data collected for both types of patterns inferred that the frequency of patterns (Basic and Combination) depends upon the sex of the lip print samples.

\section{Blind trials}

Noteworthy observations came out of the blind trials. The hard copies of original lip print samples were analysed separately and classified according to the Suzuki and Tsuchihashi system of lip print classification. According to this system, each whole print was divided into 4 quadrants and classified as Type I or Type I' and so forth, given by Suzuki and Tsuchihashi system. The same lip print samples were independently analysed according to the proposed (new) classification system, where a whole print was divided into 10 quadrants. All the whole prints were successfully classified. It was later attempted to classify some partial lip print (1/10th size of the whole print) samples and link them to their source of origin using the Suzuki and Tsuchihashi's system and the novel system of the present study as well. Some of the partial impressions (quadrants) of the Test samples could not be assigned any 
Table 5 Frequency of Combination Patterns

\begin{tabular}{|c|c|c|c|c|c|c|c|}
\hline Sr. no. & $\begin{array}{l}\text { Type of } \\
\text { Combination } \\
\text { Pattern }\end{array}$ & $\begin{array}{l}\text { Total number of } \\
\text { samples analysed }\end{array}$ & $\begin{array}{l}\text { Number } \\
\text { of samples } \\
\text { exhibiting the } \\
\text { pattern }\end{array}$ & $\begin{array}{l}\text { Total number } \\
\text { of quadrants } \\
\text { analysed }\end{array}$ & $\begin{array}{l}\text { Number of } \\
\text { quadrants } \\
\text { exhibiting the } \\
\text { pattern }\end{array}$ & $\begin{array}{l}\text { Sample-wise } \\
\text { percentage } \\
\text { distribution }\end{array}$ & $\begin{array}{l}\text { Quadrant-wise } \\
\text { percentage } \\
\text { distribution }\end{array}$ \\
\hline 1 & $L+C$ & 500 & 03 & 5000 & 03 & $0.60 \%$ & $0.06 \%$ \\
\hline 2 & $L+B$ & 500 & 47 & 5000 & 51 & $9.40 \%$ & $1.02 \%$ \\
\hline 3 & $L+C B$ & 500 & 17 & 5000 & 18 & $3.40 \%$ & $0.36 \%$ \\
\hline 4 & $L+\mid B$ & 500 & 04 & 5000 & 04 & $0.80 \%$ & $0.08 \%$ \\
\hline 5 & $\mathrm{~L}+\mathrm{ClB}$ & 500 & 04 & 5000 & 05 & $0.80 \%$ & $0.10 \%$ \\
\hline 6 & $L+S$ & 500 & 35 & 5000 & 36 & $7.00 \%$ & $0.72 \%$ \\
\hline 7 & $C+L$ & 500 & 02 & 5000 & 02 & $0.40 \%$ & $0.04 \%$ \\
\hline 8 & $C+B$ & 500 & 03 & 5000 & 04 & $0.60 \%$ & $0.08 \%$ \\
\hline 9 & $C+C B$ & 500 & 05 & 5000 & 06 & $1.00 \%$ & $0.12 \%$ \\
\hline 10 & $C+I B$ & 500 & 04 & 5000 & 05 & $0.80 \%$ & $0.10 \%$ \\
\hline 11 & $\mathrm{C}+\mathrm{ClB}$ & 500 & 03 & 5000 & 05 & $0.60 \%$ & $0.10 \%$ \\
\hline 12 & $C+S$ & 500 & 03 & 5000 & 03 & $0.60 \%$ & $0.06 \%$ \\
\hline 13 & $B+L$ & 500 & 36 & 5000 & 41 & $7.20 \%$ & $0.82 \%$ \\
\hline 14 & $B+C$ & 500 & 06 & 5000 & 06 & $1.20 \%$ & $0.12 \%$ \\
\hline 15 & $B+C B$ & 500 & 149 & 5000 & 231 & $29.80 \%$ & $4.62 \%$ \\
\hline 16 & $B+I B$ & 500 & 24 & 5000 & 26 & $4.80 \%$ & $0.52 \%$ \\
\hline 17 & $\mathrm{~B}+\mathrm{ClB}$ & 500 & 24 & 5000 & 27 & $4.80 \%$ & $0.54 \%$ \\
\hline 18 & $B+S$ & 500 & 155 & 5000 & 216 & $31.00 \%$ & $4.32 \%$ \\
\hline 19 & $C B+L$ & 500 & 27 & 5000 & 29 & $5.40 \%$ & $0.58 \%$ \\
\hline 20 & $C B+C$ & 500 & 10 & 5000 & 10 & $2.00 \%$ & $0.20 \%$ \\
\hline 21 & $C B+B$ & 500 & 94 & 5000 & 130 & $18.80 \%$ & $2.60 \%$ \\
\hline 22 & $C B+I B$ & 500 & 18 & 5000 & 20 & $3.60 \%$ & $0.40 \%$ \\
\hline 23 & $\mathrm{CB}+\mathrm{CIB}$ & 500 & 49 & 5000 & 54 & $9.80 \%$ & $1.08 \%$ \\
\hline 24 & $C B+S$ & 500 & 181 & 5000 & 279 & $36.20 \%$ & $5.58 \%$ \\
\hline 25 & $\mathrm{IB}+\mathrm{L}$ & 500 & 15 & 5000 & 16 & $3.00 \%$ & $0.32 \%$ \\
\hline 26 & $\mathrm{IB}+\mathrm{C}$ & 500 & 06 & 5000 & 06 & $1.20 \%$ & $0.12 \%$ \\
\hline 27 & $\mathrm{IB}+\mathrm{B}$ & 500 & 77 & 5000 & 96 & $15.40 \%$ & $1.92 \%$ \\
\hline 28 & $\mathrm{IB}+\mathrm{CB}$ & 500 & 135 & 5000 & 173 & $27.00 \%$ & $3.46 \%$ \\
\hline 29 & $\mathrm{IB}+\mathrm{CIB}$ & 500 & 42 & 5000 & 46 & $8.40 \%$ & $0.92 \%$ \\
\hline 30 & $\mathrm{IB}+\mathrm{S}$ & 500 & 165 & 5000 & 272 & $33.00 \%$ & $5.54 \%$ \\
\hline 31 & $\mathrm{ClB}+\mathrm{L}$ & 500 & 09 & 5000 & 09 & $1.80 \%$ & $0.18 \%$ \\
\hline 32 & $C I B+C$ & 500 & 03 & 5000 & 03 & $0.60 \%$ & $0.06 \%$ \\
\hline 33 & $\mathrm{ClB}+\mathrm{B}$ & 500 & 72 & 5000 & 82 & $14.40 \%$ & $1.64 \%$ \\
\hline 34 & $\mathrm{ClB}+\mathrm{CB}$ & 500 & 52 & 5000 & 58 & $10.40 \%$ & $1.16 \%$ \\
\hline 35 & $\mathrm{CIB}+\mathrm{IB}$ & 500 & 20 & 5000 & 22 & $4.00 \%$ & $0.44 \%$ \\
\hline 36 & $\mathrm{CIB}+\mathrm{S}$ & 500 & 129 & 5000 & 192 & $25.80 \%$ & $3.84 \%$ \\
\hline 37 & $S+L$ & 500 & 16 & 5000 & 16 & $3.20 \%$ & $0.32 \%$ \\
\hline 38 & $S+C$ & 500 & 04 & 5000 & 04 & $0.80 \%$ & $0.08 \%$ \\
\hline 39 & $S+B$ & 500 & 140 & 5000 & 199 & $28.00 \%$ & $3.98 \%$ \\
\hline 40 & $S+C B$ & 500 & 129 & 5000 & 170 & $25.80 \%$ & $3.40 \%$ \\
\hline 41 & $S+I B$ & 500 & 38 & 5000 & 48 & $7.60 \%$ & $0.96 \%$ \\
\hline 42 & $\mathrm{~S}+\mathrm{ClB}$ & 500 & 21 & 5000 & 21 & $4.20 \%$ & $0.42 \%$ \\
\hline 43 & $\mathrm{MP}$ & 500 & 168 & 5000 & 247 & $33.60 \%$ & $4.94 \%$ \\
\hline
\end{tabular}

$L$, lines; $C$, curves; $B$, bifurcations; $C B$, curved bifurcations; $I B$, intersected bifurcations; $C I B$, curved intersected bifurcations; $S$, squares; $M P$, miscellaneous pattern 


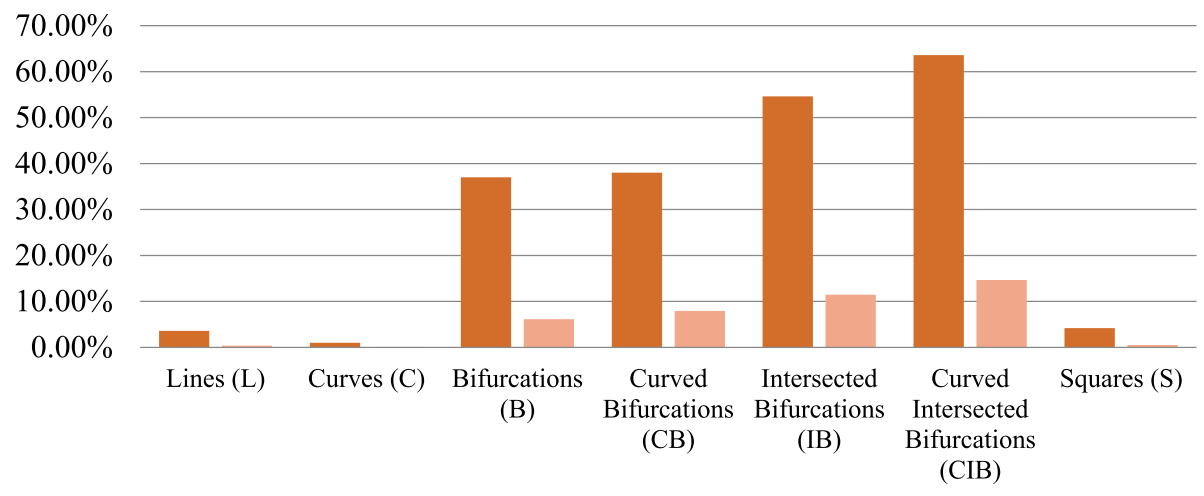

- Sample-wise percentage distribution $\square$ Quadrant-wise percentage distribution

Fig. 2 Graph showing sample-wise and quadrant-wise percentage distribution (the data is given in Table 4) of Basic Patterns

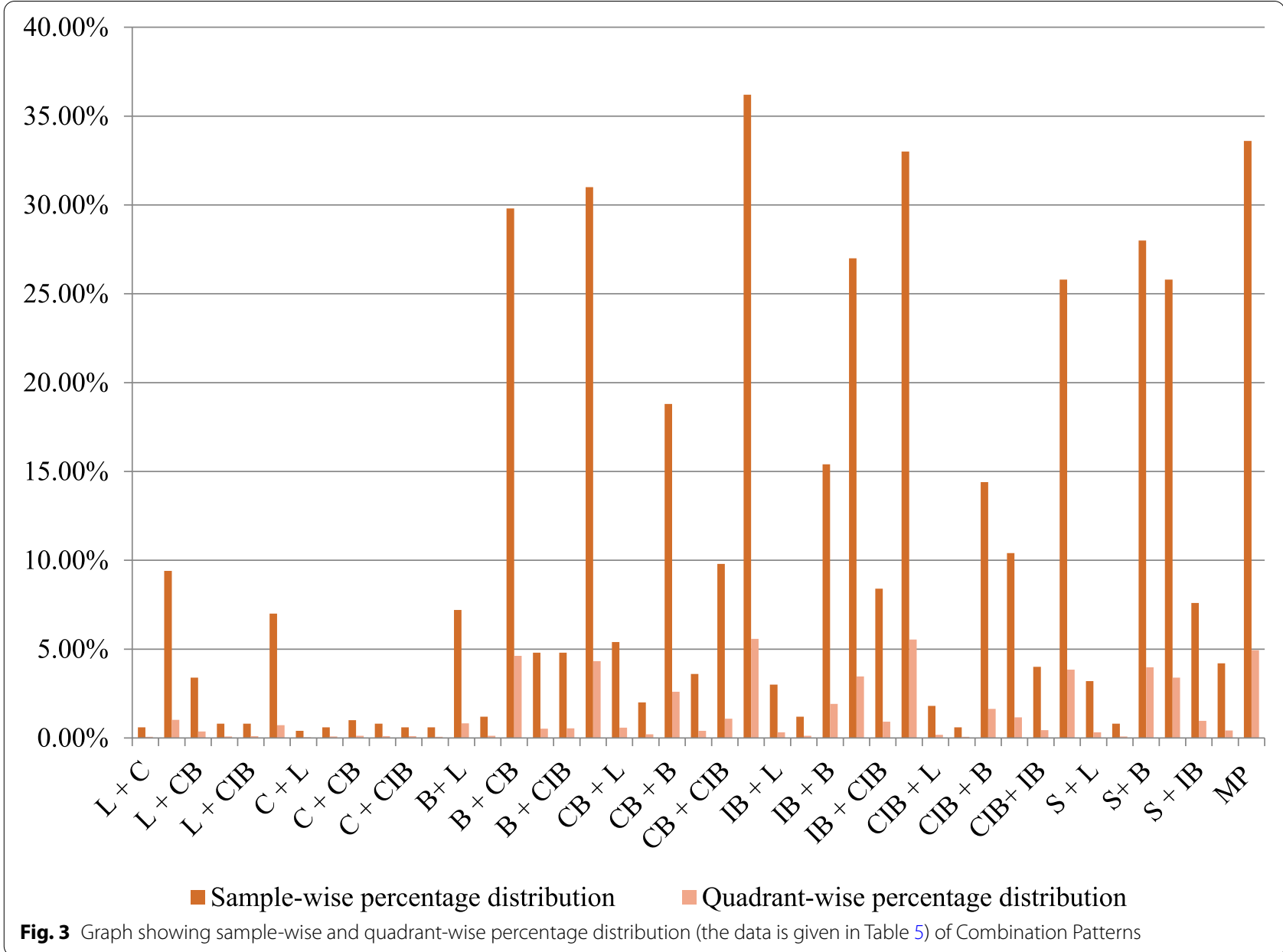

of the Suzuki and Tsuchihashi system's values or codes, like the patterns possessing horizontally aligned angular bifurcations or intersected bifurcations having curvature. The patterns which were not addressed by Suzuki and
Tsuchihashi system were classified according to the present novel alternate classification system, and the partial lip prints (quadrants) were successfully linked to their source of origin. 
Table 6 Frequency of Basic Patterns in female samples

\begin{tabular}{|c|c|c|c|c|c|c|c|}
\hline Sr. no. & $\begin{array}{l}\text { Type of } \\
\text { Basic } \\
\text { Pattern }\end{array}$ & $\begin{array}{l}\text { Number of female } \\
\text { samples analysed }\end{array}$ & $\begin{array}{l}\text { Number of } \\
\text { female samples } \\
\text { exhibiting the } \\
\text { pattern }\end{array}$ & $\begin{array}{l}\text { Number of } \\
\text { quadrants } \\
\text { analysed in } \\
\text { female samples }\end{array}$ & $\begin{array}{l}\text { Number of } \\
\text { quadrants in } \\
\text { female samples } \\
\text { exhibiting the } \\
\text { pattern }\end{array}$ & $\begin{array}{l}\text { Sample-wise } \\
\text { frequency of } \\
\text { patterns in female } \\
\text { samples }\end{array}$ & $\begin{array}{l}\text { Quadrant-wise } \\
\text { frequency of } \\
\text { patterns in female } \\
\text { samples }\end{array}$ \\
\hline 1 & L & 100 & 01 & 1000 & 01 & $1.00 \%$ & $0.10 \%$ \\
\hline 2 & C & 100 & 01 & 1000 & 01 & $1.00 \%$ & $0.10 \%$ \\
\hline 3 & B & 100 & 36 & 1000 & 51 & $36.00 \%$ & $5.10 \%$ \\
\hline 4 & $C B$ & 100 & 50 & 1000 & 115 & $50.00 \%$ & $11.50 \%$ \\
\hline 5 & IB & 100 & 46 & 1000 & 99 & $46.00 \%$ & $9.90 \%$ \\
\hline 6 & $\mathrm{ClB}$ & 100 & 82 & 1000 & 202 & $82.00 \%$ & $20.20 \%$ \\
\hline 7 & S & 100 & 07 & 1000 & 08 & $7.00 \%$ & $0.80 \%$ \\
\hline
\end{tabular}

$L$, lines; $C$, curves; $B$, bifurcations; $C B$, curved bifurcations; $I B$, intersected bifurcations; $C I B$, curved intersected bifurcations; $S$, squares

Table 7 Frequency of Basic Patterns in male samples

\begin{tabular}{|c|c|c|c|c|c|c|c|}
\hline Sr. no. & $\begin{array}{l}\text { Type of } \\
\text { Basic } \\
\text { Pattern }\end{array}$ & $\begin{array}{l}\text { Number of male } \\
\text { samples analysed }\end{array}$ & $\begin{array}{l}\text { Number of } \\
\text { male samples } \\
\text { exhibiting the } \\
\text { pattern }\end{array}$ & $\begin{array}{l}\text { Number of } \\
\text { quadrants } \\
\text { analysed in male } \\
\text { samples }\end{array}$ & $\begin{array}{l}\text { Number of } \\
\text { quadrants in male } \\
\text { samples exhibiting } \\
\text { the pattern }\end{array}$ & $\begin{array}{l}\text { Sample-wise } \\
\text { frequency of } \\
\text { patterns in male } \\
\text { samples }\end{array}$ & $\begin{array}{l}\text { Quadrant-wise } \\
\text { frequency of } \\
\text { patterns in male } \\
\text { samples }\end{array}$ \\
\hline 1 & L & 100 & 05 & 1000 & 05 & $5.00 \%$ & $0.50 \%$ \\
\hline 2 & C & 100 & 00 & 1000 & 00 & $0.00 \%$ & $0.00 \%$ \\
\hline 3 & B & 100 & 59 & 1000 & 119 & $59.00 \%$ & $11.90 \%$ \\
\hline 4 & $C B$ & 100 & 48 & 1000 & 95 & $48.00 \%$ & $9.50 \%$ \\
\hline 5 & IB & 100 & 17 & 1000 & 23 & $17.00 \%$ & $2.30 \%$ \\
\hline 6 & $\mathrm{CIB}$ & 100 & 59 & 1000 & 114 & $59.00 \%$ & $11.40 \%$ \\
\hline 7 & S & 100 & 02 & 1000 & 02 & $2.00 \%$ & $0.20 \%$ \\
\hline
\end{tabular}

$L$, lines; $C$, curves; $B$, bifurcations; $C B$, curved bifurcations; $I B$, intersected bifurcations; $C I B$, curved intersected bifurcations; $S$, squares

\section{Discussion}

Lips are two exceptionally delicate, movable, versatile folds made of skin, muscle, glands and mucous layer, and encompass the oral opening. Lips act as the opening for food consumption and the medium of sound and speech. These skin overlays are covered by a mucosal layer which bears certain elevations and depressions, unique to every individual. The aforementioned, highly inimitable skin folds constitute the lip prints.

If an investigator encounters lipstick stains on a suspect's clothing, there is always a possibility to ascertain a link between the perpetrator and the victim with the help of cosmetic evidence (lipstick) used. If some beverages or drinks have been consumed or some clothes, tissue or napkin, and so forth have been used either by the suspect or victim, lip prints can be used to confirm the involvement of a person in that particular criminal act. Besides bite marks on food products, lip prints can often be located on the window panes, doors, paintings, plastic bags, and so forth.

On several occasions, lip forensics has been successfully used to put criminals behind the bars, as they are unique and permanent like fingerprints (Sivapathasundharam et al. 2001; Tsuchihashi 1974) and acceptable in the court of law. When the pattern is not clear, a person could be caught by analysing the trace evidence such as lipstick stained with saliva. DNA typing can also be successfully carried out from lip prints having saliva (Webb et al. 2001). A lip print recovered at a crime scene can pinpoint the corpus delicti, number and sex of people involved, type of cosmetics used, habits or occupational traits, and pathological conditions (if any) existing in lips (Kasprzak 1990).

A variety of demographic studies (Harqad et al. 2014; Badiye and Kapoor 2016; Kaul et al. 2017; Manjusha et al. 2017; Ahmed et al. 2018) have been conducted in the discipline of Lip forensics to ascertain the evidentiary value of human lips in linking the victim and suspect to the crime scene. Various authors (Badiye and Kapoor 2016; Kaul et al. 2017; Ahmed et al. 2018) have studied the morphological variations in the lip print patterns of individuals belonging to different races and regions. Manjusha et al. (2017) analysed the relationship between lip print patterns with Type 2 diabetes. Harqad et al. (2014) 
Table 8 Frequency of Combination Patterns in female samples

\begin{tabular}{|c|c|c|c|c|c|c|c|}
\hline Sr. no. & $\begin{array}{l}\text { Type of } \\
\text { Combination } \\
\text { Pattern }\end{array}$ & $\begin{array}{l}\text { Total number of } \\
\text { female samples } \\
\text { analysed }\end{array}$ & $\begin{array}{l}\text { Number of } \\
\text { female samples } \\
\text { exhibiting the } \\
\text { pattern }\end{array}$ & $\begin{array}{l}\text { Total number } \\
\text { of quadrants } \\
\text { analysed in } \\
\text { female samples }\end{array}$ & $\begin{array}{l}\text { Number of } \\
\text { quadrants in } \\
\text { female samples } \\
\text { exhibiting the } \\
\text { pattern }\end{array}$ & $\begin{array}{l}\text { Sample-wise } \\
\text { frequency of } \\
\text { patterns in } \\
\text { female samples }\end{array}$ & $\begin{array}{l}\text { Quadrant-wise } \\
\text { frequency of } \\
\text { patterns in female } \\
\text { samples }\end{array}$ \\
\hline 1 & $L+C$ & 100 & 01 & 1000 & 01 & $1.00 \%$ & $0.10 \%$ \\
\hline 2 & $L+B$ & 100 & 08 & 1000 & 11 & $8.00 \%$ & $1.10 \%$ \\
\hline 3 & $L+C B$ & 100 & 02 & 1000 & 02 & $2.00 \%$ & $0.20 \%$ \\
\hline 4 & $L+I B$ & 100 & 03 & 1000 & 03 & $3.00 \%$ & $0.30 \%$ \\
\hline 5 & $\mathrm{~L}+\mathrm{ClB}$ & 100 & 01 & 1000 & 02 & $1.00 \%$ & $0.20 \%$ \\
\hline 6 & $L+S$ & 100 & 16 & 1000 & 17 & $16.00 \%$ & $1.70 \%$ \\
\hline 7 & $C+L$ & 100 & 01 & 1000 & 01 & $1.00 \%$ & $0.10 \%$ \\
\hline 8 & $C+B$ & 100 & 01 & 1000 & 01 & $1.00 \%$ & $0.10 \%$ \\
\hline 9 & $C+C B$ & 100 & 02 & 1000 & 02 & $2.00 \%$ & $0.20 \%$ \\
\hline 10 & $C+I B$ & 100 & 01 & 1000 & 02 & $1.00 \%$ & $0.20 \%$ \\
\hline 11 & $\mathrm{C}+\mathrm{ClB}$ & 100 & 01 & 1000 & 01 & $1.00 \%$ & $0.10 \%$ \\
\hline 12 & $C+S$ & 100 & 01 & 1000 & 01 & $1.00 \%$ & $0.10 \%$ \\
\hline 13 & $B+L$ & 100 & 13 & 1000 & 16 & $13.00 \%$ & $1.60 \%$ \\
\hline 14 & $B+C$ & 100 & 02 & 1000 & 02 & $2.00 \%$ & $0.20 \%$ \\
\hline 15 & $B+C B$ & 100 & 20 & 1000 & 24 & $20.00 \%$ & $2.40 \%$ \\
\hline 16 & $B+I B$ & 100 & 05 & 1000 & 05 & $5.00 \%$ & $0.50 \%$ \\
\hline 17 & $\mathrm{~B}+\mathrm{CIB}$ & 100 & 03 & 1000 & 03 & $3.00 \%$ & $0.30 \%$ \\
\hline 18 & $B+S$ & 100 & 32 & 1000 & 47 & $32.00 \%$ & $4.70 \%$ \\
\hline 19 & $\mathrm{CB}+\mathrm{L}$ & 100 & 07 & 1000 & 08 & $7.00 \%$ & $0.80 \%$ \\
\hline 20 & $\mathrm{CB}+\mathrm{C}$ & 100 & 01 & 1000 & 01 & $1.00 \%$ & $0.10 \%$ \\
\hline 21 & $C B+B$ & 100 & 23 & 1000 & 31 & $23.00 \%$ & $3.10 \%$ \\
\hline 22 & $\mathrm{CB}+\mathrm{IB}$ & 100 & 03 & 1000 & 03 & $3.00 \%$ & $0.30 \%$ \\
\hline 23 & $\mathrm{CB}+\mathrm{CIB}$ & 100 & 14 & 1000 & 16 & $14.00 \%$ & $1.60 \%$ \\
\hline 24 & $C B+S$ & 100 & 37 & 1000 & 48 & $37.00 \%$ & $4.80 \%$ \\
\hline 25 & $\mathrm{IB}+\mathrm{L}$ & 100 & 08 & 1000 & 08 & $8.00 \%$ & $0.80 \%$ \\
\hline 26 & $\mathrm{IB}+\mathrm{C}$ & 100 & 01 & 1000 & 01 & $1.00 \%$ & $0.10 \%$ \\
\hline 27 & $\mathrm{IB}+\mathrm{B}$ & 100 & 26 & 1000 & 33 & $26.00 \%$ & $3.30 \%$ \\
\hline 28 & $\mathrm{IB}+\mathrm{CB}$ & 100 & 53 & 1000 & 76 & $53.00 \%$ & $7.60 \%$ \\
\hline 29 & $\mathrm{IB}+\mathrm{ClB}$ & 100 & 17 & 1000 & 19 & $17.00 \%$ & $1.90 \%$ \\
\hline 30 & $\mathrm{IB}+\mathrm{S}$ & 100 & 45 & 1000 & 78 & $45.00 \%$ & $7.80 \%$ \\
\hline 31 & $C I B+L$ & 100 & 02 & 1000 & 02 & $2.00 \%$ & $0.20 \%$ \\
\hline 32 & $C I B+C$ & 100 & 01 & 1000 & 03 & $1.00 \%$ & $0.30 \%$ \\
\hline 33 & $C I B+B$ & 100 & 23 & 1000 & 26 & $23.00 \%$ & $2.60 \%$ \\
\hline 34 & $\mathrm{ClB}+\mathrm{CB}$ & 100 & 10 & 1000 & 11 & $10.00 \%$ & $1.10 \%$ \\
\hline 35 & $\mathrm{CIB}+\mathrm{IB}$ & 100 & 03 & 1000 & 03 & $3.00 \%$ & $0.30 \%$ \\
\hline 36 & $\mathrm{CIB}+\mathrm{S}$ & 100 & 24 & 1000 & 28 & $24.00 \%$ & $2.80 \%$ \\
\hline 37 & $S+L$ & 100 & 07 & 1000 & 07 & $7.00 \%$ & $0.70 \%$ \\
\hline 38 & $S+C$ & 100 & 01 & 1000 & 01 & $1.00 \%$ & $0.10 \%$ \\
\hline 39 & $S+B$ & 100 & 49 & 1000 & 71 & $49.00 \%$ & $7.10 \%$ \\
\hline 40 & $S+C B$ & 100 & 20 & 1000 & 23 & $20.00 \%$ & $2.30 \%$ \\
\hline 41 & $S+I B$ & 100 & 21 & 1000 & 26 & $21.00 \%$ & $2.60 \%$ \\
\hline 42 & $\mathrm{~S}+\mathrm{CIB}$ & 100 & 03 & 1000 & 03 & $3.00 \%$ & $0.30 \%$ \\
\hline 43 & MP & 100 & 57 & 1000 & 89 & $57.00 \%$ & $8.90 \%$ \\
\hline
\end{tabular}


Table 9 Frequency of Combination Patterns in male samples

\begin{tabular}{|c|c|c|c|c|c|c|c|}
\hline Sr. no. & $\begin{array}{l}\text { Type of } \\
\text { Combination } \\
\text { Pattern }\end{array}$ & $\begin{array}{l}\text { Total number of } \\
\text { male samples } \\
\text { analysed }\end{array}$ & $\begin{array}{l}\text { Number of } \\
\text { male samples } \\
\text { exhibiting the } \\
\text { pattern }\end{array}$ & $\begin{array}{l}\text { Total number } \\
\text { of quadrants } \\
\text { analysed in male } \\
\text { samples }\end{array}$ & $\begin{array}{l}\text { Number of } \\
\text { quadrants in } \\
\text { male samples } \\
\text { exhibiting the } \\
\text { pattern }\end{array}$ & $\begin{array}{l}\text { Sample-wise } \\
\text { frequency of } \\
\text { patterns in male } \\
\text { samples }\end{array}$ & $\begin{array}{l}\text { Quadrant-wise } \\
\text { frequency of } \\
\text { patterns in male } \\
\text { samples }\end{array}$ \\
\hline 1 & $L+C$ & 100 & 00 & 1000 & 00 & $0.00 \%$ & $0.00 \%$ \\
\hline 2 & $L+B$ & 100 & 15 & 1000 & 16 & $15.00 \%$ & $1.60 \%$ \\
\hline 3 & $L+C B$ & 100 & 07 & 1000 & 08 & $7.00 \%$ & $0.80 \%$ \\
\hline 4 & $L+I B$ & 100 & 00 & 1000 & 00 & $0.00 \%$ & $0.00 \%$ \\
\hline 5 & $\mathrm{~L}+\mathrm{ClB}$ & 100 & 02 & 1000 & 02 & $2.00 \%$ & $0.20 \%$ \\
\hline 6 & $L+S$ & 100 & 04 & 1000 & 04 & $4.00 \%$ & $0.40 \%$ \\
\hline 7 & $C+L$ & 100 & 01 & 1000 & 01 & $1.00 \%$ & $0.10 \%$ \\
\hline 8 & $C+B$ & 100 & 00 & 1000 & 00 & $0.00 \%$ & $0.00 \%$ \\
\hline 9 & $C+C B$ & 100 & 02 & 1000 & 03 & $2.00 \%$ & $0.30 \%$ \\
\hline 10 & $C+I B$ & 100 & 00 & 1000 & 00 & $0.00 \%$ & $0.00 \%$ \\
\hline 11 & $\mathrm{C}+\mathrm{ClB}$ & 100 & 00 & 1000 & 00 & $0.00 \%$ & $0.00 \%$ \\
\hline 12 & $C+S$ & 100 & 02 & 1000 & 02 & $2.00 \%$ & $0.20 \%$ \\
\hline 13 & $B+L$ & 100 & 08 & 1000 & 09 & $8.00 \%$ & $0.90 \%$ \\
\hline 14 & $B+C$ & 100 & 01 & 1000 & 01 & $1.00 \%$ & $0.10 \%$ \\
\hline 15 & $B+C B$ & 100 & 65 & 1000 & 118 & $65.00 \%$ & $11.80 \%$ \\
\hline 16 & $B+I B$ & 100 & 04 & 1000 & 04 & $4.00 \%$ & $0.40 \%$ \\
\hline 17 & $\mathrm{~B}+\mathrm{ClB}$ & 100 & 12 & 1000 & 14 & $12.00 \%$ & $1.40 \%$ \\
\hline 18 & $B+S$ & 100 & 33 & 1000 & 39 & $33.00 \%$ & $3.90 \%$ \\
\hline 19 & $\mathrm{CB}+\mathrm{L}$ & 100 & 09 & 1000 & 10 & $9.00 \%$ & $1.00 \%$ \\
\hline 20 & $\mathrm{CB}+\mathrm{C}$ & 100 & 02 & 1000 & 02 & $2.00 \%$ & $0.20 \%$ \\
\hline 21 & $C B+B$ & 100 & 49 & 1000 & 76 & $49.00 \%$ & $7.60 \%$ \\
\hline 22 & $C B+I B$ & 100 & 04 & 1000 & 04 & $4.00 \%$ & $0.40 \%$ \\
\hline 23 & $C B+C I B$ & 100 & 23 & 1000 & 26 & $23.00 \%$ & $2.60 \%$ \\
\hline 24 & $C B+S$ & 100 & 35 & 1000 & 51 & $35.00 \%$ & $5.10 \%$ \\
\hline 25 & $\mathrm{IB}+\mathrm{L}$ & 100 & 00 & 1000 & 00 & $0.00 \%$ & $0.00 \%$ \\
\hline 26 & $\mathrm{IB}+\mathrm{C}$ & 100 & 02 & 1000 & 02 & $2.00 \%$ & $0.20 \%$ \\
\hline 27 & $\mathrm{IB}+\mathrm{B}$ & 100 & 11 & 1000 & 12 & $11.00 \%$ & $1.20 \%$ \\
\hline 28 & $\mathrm{IB}+\mathrm{CB}$ & 100 & 25 & 1000 & 30 & $25.00 \%$ & $3.00 \%$ \\
\hline 29 & $\mathrm{IB}+\mathrm{CIB}$ & 100 & 04 & 1000 & 04 & $4.00 \%$ & $0.40 \%$ \\
\hline 30 & $\mathrm{IB}+\mathrm{S}$ & 100 & 06 & 1000 & 06 & $6.00 \%$ & $0.60 \%$ \\
\hline 31 & $\mathrm{CIB}+\mathrm{L}$ & 100 & 04 & 1000 & 04 & $4.00 \%$ & $0.40 \%$ \\
\hline 32 & $C I B+C$ & 100 & 00 & 1000 & 00 & $0.00 \%$ & $0.00 \%$ \\
\hline 33 & $C I B+B$ & 100 & 27 & 1000 & 33 & $27.00 \%$ & $3.30 \%$ \\
\hline 34 & $\mathrm{ClB}+\mathrm{CB}$ & 100 & 19 & 1000 & 20 & $19.00 \%$ & $2.00 \%$ \\
\hline 35 & $\mathrm{CIB}+\mathrm{IB}$ & 100 & 03 & 1000 & 04 & $3.00 \%$ & $0.40 \%$ \\
\hline 36 & $\mathrm{ClB}+\mathrm{S}$ & 100 & 16 & 1000 & 26 & $16.00 \%$ & $2.60 \%$ \\
\hline 37 & $S+L$ & 100 & 01 & 1000 & 01 & $1.00 \%$ & $0.10 \%$ \\
\hline 38 & $S+C$ & 100 & 01 & 1000 & 01 & $1.00 \%$ & $0.10 \%$ \\
\hline 39 & $S+B$ & 100 & 15 & 1000 & 18 & $15.00 \%$ & $1.80 \%$ \\
\hline 40 & $\mathrm{~S}+\mathrm{CB}$ & 100 & 17 & 1000 & 22 & $17.00 \%$ & $2.20 \%$ \\
\hline 41 & $S+I B$ & 100 & 03 & 1000 & 03 & $3.00 \%$ & $0.30 \%$ \\
\hline 42 & $\mathrm{~S}+\mathrm{ClB}$ & 100 & 02 & 1000 & 02 & $2.00 \%$ & $0.20 \%$ \\
\hline 43 & MP & 100 & 42 & 1000 & 62 & $42.00 \%$ & $6.20 \%$ \\
\hline
\end{tabular}


have compared the lip wrinkle patterns of Smokers and Non-smokers to locate the significant differences. Various researchers have classified lip prints based on different keys and formulas. In the previous studies conducted by different scientists, the lip prints have been classified only on the basis of the shape of wrinkles and grooves. Santos (1967) was the first researcher to classify the lip print patterns. He formulated a system of classification of lip prints by dividing the lip prints into four types (straight line, curved line, angled line, a sine curved).

Suzuki and Tsuchihashi (1971), two Japanese scientists carried out an extensive research on lip prints. They proposed the most widely used classification system of lip prints. They studied the natural lip marks or fissures and formulated a system to classify the lip prints. They proposed six different types of patterns, i.e. Type I: Long vertical (Clear-cut vertical grooves that run across the lips); Type I': Short vertical (Partial length groove of type I); Type II: Branched grooves (Branching Y-shaped pattern); Type III: Intersected grooves (Criss-cross or ' $\mathrm{x}$ ' pattern grooves); Type IV: Reticular pattern (Grooves that forms rectangular shape) and Type V: Mixed or Indefinite (Grooves that do not fall into any of the above categories, combination of two or more patterns and/or cannot be differentiated morphologically or undetermined).

Renaud (1973) endowed the field of cheiloscopy with his significant study and recommended another classification system of lip prints. Lip prints were divided into 10 types: A: Complete Vertical, B: Incomplete Vertical, C: Complete Bifurcated, D: Incomplete Bifurcated, E: Complete Branched, F: Incomplete Branched, G: Reticular pattern, H: X or comma type, I: Horizontal, J: other forms (ellipse, triangle). In 1978, Afchar Bayar recommended the classification system based on the six types of grooves, which is A1: Vertical and straight groove, covering the whole lip; A2: like the former, but not covering the whole lip; B1: Straight branched grooves; B2: Angulated branched grooves; C: Converging grooves; D: Reticular pattern grooves and E: Other grooves.

In 1974, Tsuchihashi had meanwhile given an important observation that the lip print did not consist of simply one type of pattern alone, but a mixture of varying types (Tsuchihashi 1974). No efforts have been made till date, to carry an extensive delve into the details of Tsuchihashi's observation. However, in the present study, a wide-ranging alternate system to classify the lip print impressions has been suggested. All the classification systems of lip prints devised previously have been based on the presupposition that the wrinkles and grooves present on the lips are of various shapes and sizes. Whereas, the method of categorisation of lip prints attempted in this study was entirely based upon the spatial arrangement, direction of slant, angularity, concurrence, and numerical superiority of various forms of furrows and grooves present on lips.

In the present study, lip print samples have been collected by using the most widely used tape lifting method. Prior to the application of lip colour, the subjects were being told to rub and moisten their lips with a hypoallergenic lip balm in order to nullify the chances of occurrence of any subsequent allergy. However, people with known hypersensitivity to cosmetics were not included in the research. Individuals possessing any scars, moles, inflammation, or diseased condition were also excluded from the study as these features are highly distinctive in themselves. Additionally, while choosing the lipstick, a brief description of the ingredients of various lipstick brands was enlisted and the lipstick having comparatively more organic constituents was selected. Moreover, the samples were obtained in a closed-mouth position because with the mouth wideopen, the lines present on lips disrupt a little and the lip impression gets altered.

While analysing the samples, the digital image (soft copy) of each sample was divided into 10 mathematically equivalent portions in order to study every nook and corner of the lip prints. These quadrants were assumed as partial lip prints. In total, 5000 partial lip prints (quadrants) were studied in detail and the observations were schematically tabulated.

The lip print patterns deduced in the study could be visibly told apart from each other because of the presence of vivid geometrical shapes and the aforementioned structural features. As an out-come of the study, 7 types and 51 sub-types of Basic Patterns were assorted. Theoretically, 43 types and 2550 sub-types of Combination Patterns could be variegated, when 51 sub-types of Basic Patterns are present together in a questioned or standard lip print produced by humans. Out of the 500 lip samples analysed, every lip print was found to be unique. When the pattern type appeared to be similar, detailed examination and comparison of inclination or orientation or angularity showed remarkable differences among the patterns. Henceforth, this observation is in approbation of the study conducted by Suzuki and Tsuchihashi (1970) and Tsuchihashi (1974) where they concluded that no two lip prints show the same pattern.

Furthermore, the repetitive occurrence of lip patterns (Basic and Combination) was methodically studied across the sample size (500 lip prints and 5000 partial lip prints). The majority of Basic and Combination Patterns were frequently distributed all over the lip print samples studied. However, only a few of them were scarcely present throughout the samples, like the Basic pattern 'Curve' and various Combination patterns possessing Curves as the major and minor patterns. This feature emerges with 
its own significance in narrowing down the search area in forensic investigations when lip prints are encountered as evidence. The rare occurrence of such patterns becomes an individualistic characteristic and further helps in pinpointing the identity of the depositor of lip prints. Unlike the previous classification systems, which had no provision for any curved structural patterns in lip print analysis, the predominance of 'Curved Intersected Bifurcations' and 'Curved Bifurcations' implied that these patterns are widely distributed and present a solid means for redefining the lip print classification scheme. The Basic and Combination Patterns were randomly and frequently present in the partial prints or quadrants analysed in the present study. The observations implied that even the partial prints belonging to different lip regions of the same individual are dissimilar as they never possess the same structural features (patterns).

Gender-based differences in the frequency of various Basic and Combination Patterns found in the female and male samples implicated that some of the Basic and Combination Patterns were exclusively found only in the present study's female subjects. The Statistical analysis also indicated sexual dimorphism of the Basic and Combination Patterns. Albeit various Basic and Combination Patterns showed predominance in one of the sexes (female or male), most of the patterns were not confined to a particular gender. It implied that sexual dimorphism could be determined when the lip print evidence possesses exclusively found Basic and Combination Patterns defined in the present study. The above-said finding was in approbation of the recent studies conducted by Ragab et al. (2013), Krishnan et al. (2016), and Ayuba et al. (2019), who claimed that the lip print patterns could help determine the sex of the depositor.

The classification system of lip prints proposed in this study is comprehensive and complies with the important observation made earlier by Tsuchihashi (1974). Furthermore, this alternate classification method was successfully used to classify lip prints in the blind trials conducted on a few samples. Based on the preliminary findings of blind trials, a generalized table was designed to redefine various lip print patterns in the present study. The task of classifying, searching, and matching partial impressions with the Test samples seemed quite a tough job with the most commonly used Suzuki and Tsuchihashi's system of lip print classification. However, with the currently proposed classification system, the digitalized partial lip prints were successfully linked to their source (Test samples).

Personal identification using lip print evidence follows the fundamental Law of Comparison. Questioned lip print samples recovered from the crime scene are compared with Standard or Control lip print samples taken from various suspects associated with a particular case. The comparison process consists of two stages; the first stage involves excluding dissimilar lip prints based on the shape of wrinkles (structural differences). The second stage involves matching/non-matching based on the evaluation of Kasprzak's individual classification (microstructural feature analysis) (Kasprzak 2000). The present classification system ensures to define the nature and characteristics of lip print patterns from various aspects such as shape, angularity, and direction of the lip wrinkles. Such detailed information narrows down the search area by excluding entirely dissimilar prints when an unknown lip print impression recovered from a crime scene is objectively interpreted and compared with the suspect or known lip print samples. Even closely resembling lip prints originating from different sources may seem to have similar geometrical shapes of Basic or Combination patterns. However, there are negligible chances that the spatial arrangement of wrinkles and the position of such patterns in different lip regions may ever be precisely similar.

Moreover, the incidences of rare patterns further elucidate the chances of linking the lip print evidence to its source of origin. Additionally, comparing the number and position of various second-level details given by Kasprzak (2000) exclusively establishes a match or non-match between closely related questioned and standard lip print samples. Henceforth, the results concluded from this study are fervently capable of differentiating various people's lip prints, thereby helping in individualisation.

At times, the investigator may come across fragmented prints at the crime scene. Another possibility is to recover an incomplete lip print belonging to people either having oral pathological conditions or the habit of chain-smoking. In such cases, assessing the features or patterns possessed by the questioned and standard lip print samples at quadrant levels becomes of utmost importance. When amalgamated with Kasprzak's Individual Characteristic system (Kasprzak 2000), the current system presents an effective way of classifying and highlighting the structural features of lip wrinkles, even when the evidence is found partially (incomplete prints) at the crime scene.

To summarize, the aforementioned classification system can be used as a substitute to the former classification systems, which did not have any provision for the Combination Patterns present in the lip prints and their different regions (quadrants). It is expected to concretise the area of the quest; instead, it would ultimately entail individualisation.

\section{Limitations}

The quality of lip impressions is one of the major limiting factors that need consideration for being able to be 
classified using any of the available lip print classification systems. The lip impression has to be at least that much clear (with a sufficient number of comparable features) so that the investigator may handily categorize the patterns and locate the individual characters present therein. Smudged prints without adequate details are not likely to be comparable. Partial latent lip impressions also add to the limitation, as in the development of latent lip impressions, some of the identifying features get smudged/ destroyed. Standard (known or known control) samples are required to compare and identify the individual.

The lack of availability of a suspect or candidate lip print database is another limitation, as well as the fact that further studies need to be carried out. Until enough data is available, either partial or whole lip impressions recovered from the crime scene cannot be compared and linked to the source. Accordingly, there is a need to have a robust alternate method, which can classify all types of lip prints and even the partial prints. For which further exhaustive studies should be conducted among different populations of the world. Further, in the era of technology, there is an urgent need to generate a database with the capability to record and store lip prints collected from individuals accused of committing crimes or convicted by the court of law.

\section{Conclusions}

In the present study, an alternative method of classifying the lip prints was devised. To accomplish the purpose, the whole lip (Klein's zone) impressions were divided into ten quadrants (five on the upper lip and remaining five on the lower lip). The following conclusions emerged out from the study:

- In contrast to the earlier devised classification systems of lip prints (Suzuki and Tsuchihashi, Martin Santos, Renaud, Afchar Bayar, and Jose Maria Dominguez) which were based completely on the shape of patterns only, the method used in this study lays emphasis on the structural arrangement of wrinkles and grooves forming various types of patterns, which can be categorized as Basic and Combination Patterns.

- The lip print patterns can be classified into 7 types of Basic Patterns and 43 types of Combination Patterns, both having various sub-types on the basis of direction and orientation of lines constituting the original pattern.

- In certain quadrants, only one type of pattern i.e. Basic Pattern may be present, while the others may consist of a mixture of more than one Basic pattern to form a Combination Pattern.
Keeping in mind the consistent presence of these patterns, the conclusions drawn from this study seem to be very important and are capable of classifying even a smaller fragment (1/10th) of the lip print recovered from a crime scene, irrefutably.

\section{Abbreviations}

USA: United Stated of America; .jpeg: Joint Photographic Experts Group; viz: Which is or that is to say; i.e.: That is or in other words.

\section{Acknowledgements}

We are thankful to the University Grants Commission, New Delhi, for providing fellowship (UGC-NET) and contingent grant to the primary author to carry out the present research work in the form of JRF [grant number 33001/(NET-DEC. 2014)].

\section{Authors' contributions}

JK was involved in the conceptualisation, methods design, data curation, validation, formal analysis, investigation, writing the original draft of the manuscript, and funding acquisition. MKT contributed to the conceptualisation, supervision, reviewing and editing the manuscript, and project administration. All authors have read and approved the final manuscript.

\section{Funding}

This work was supported by the University Grants Commission, New Delhi, India [grant number 33001/(NET-DEC. 2014)], in the form of Junior Research Fellowship to JK

\section{Availability of data and materials}

The datasets generated during and/or analysed during the current study are available from the corresponding author on reasonable request.

\section{Declarations}

\section{Ethics approval and consent to participate}

The study protocol was approved by the Institutional Ethical Committee, Punjabi University Patiala; Reference Number: IEC 2017/06 dated 20-01-2017. Written informed consent was obtained from the study participants.

\section{Consent for publication}

Consent for publication was obtained from every volunteer in the form of Participant Informed Consent Form (PICF).

\section{Competing interests}

The authors declare that they have no competing interests.

Received: 4 December 2020 Accepted: 24 October 2021

Published online: 27 November 2021

\section{References}

Ahmed SA, Salem HE, Fawzy MM (2018) Forensic dissection of lip print as an investigative tool in a mixed Egyptian population. Alexandria J Med 54(3):235-239 https://doi.org/10.1016/j.ajme.2017.08.002

Ayuba JT, Echoru I, Ssempijja F, Ann ML, Edgar F, Buhari M (2019) Sexual dimorphism in the lip print pattern and size among Ugandan, Kenyan and Somali population. Forensic Sci Int: Rep 1:100012 https://doi.org/10. 1016/j.fsir.2019.100012

Badiye A, Kapoor N (2016) Morphologic variations of lip-print patterns in a central Indian population: a preliminary study. Med Sci Law 56(3):200204 https://doi.org/10.1177/0025802415605538

Caldas IM, Magalhāes T, Afonso A (2007) Establishing identity using cheiloscopy and palatoscopy. Forensic Sci Int 165(1):1-9 https://doi.org/10. 1016/j.forsciint.2006.04.010 
Castelló A, Seguí MA, Verdú F (2005) Luminous lip-prints as criminal evidence. Forensic Sci Int 155(2-3):185-187 https://doi.org/10.1016/j.forsciint.2004. 12.005

Cummins H, Midlo C (1961) Finger prints, palms and soles: an introduction to Dermatoglyphics Dover Publications, New York https://wwwoeawacat/ resources/Record/990000923110504498 Accessed May 2021

Fonseca GM, Contreras JO, Lagos CR, Lázaro SL (2019) Lip print identification: current perspectives. J Forensic Legal Med 65:32-38 https://doi.org/10. 1016/j.jlm.2019.04.009

George R, Afandi NSBN, Abidin SNHBZ, Ishak NIB, Soe HHK, Ismail ARH (2016) Inheritance pattern of lip prints among Malay population: a pilot study. J Forensic Legal Med 39:156-160 https://doi.org/10.1016/j.jlm.2016.01.021 Harqad TM, Dardjan M, Hardjadinata IS (2014) Wrinkle lip pattern in smokers and non-smokers for identification in forensic dentistry. Padjadjaran J Dent 26(1):87-90 https://doi.org/10.24198/pjd.vol26no1.26761

Hirth L, Göttsche H, Goedde HW (1975) Lip prints-variability and genetics (author's transl). Humangenetik 30(1):47-62 https://doi.org/10.1007/ bf00273631

Kasprzak J (1990) Possibilities of cheiloscopy. Forensic Sci Int 46(1-2):145-151 https://doi.org/10.1016/0379-0738(90)90154-Q

Kasprzak J (2000) Cheiloscopy. In: Siegal JA, Saukko PJ, Knupfer GC (eds) encyclopedia of forensic sciences, vol 1. Elsevier, p 358-362. https://doi.org/10. 1006/rwfs.2000.0436

Kaul R, Shilpa PS, Padmashree S, Bhat S, Sultana N (2017) Study of lip prints in different ethno-racial groups in India. Indian J Dent Res 28(5):545-548 https://doi.org/10.4103/ijdr.ijdr_352_14

Krishnan RP, Thangavelu R, Rathnavelu V, Narasimhan M (2016) Gender determination: role of lip prints, finger prints and mandibular canine index. Exp Therap Med 11(6):2329-2332 https://doi.org/10.3892/etm.2016.3245

Loganadan S, Dardjan M, Murniati N, Oscandar F, Malinda Y, Zakiawati D (2019) Preliminary research: description of lip print patterns in children and their parents among Deutero-Malay population in Indonesia. Int J Dent 2019:1-6 https://doi.org/10.1155/2019/7629146

Mala S, Rathod V, Pundir S, Dixit S (2017) Pattern self-repetition of fingerprints, lip prints, and palatal rugae among three generations of family: a forensic approach to identify family hierarchy. J Forensic Dent Sci 9(1):15-19 https://www.ncbi.nlm.nih.gov/pubmed/28584469
Manjusha P, Sudha S, Shameena PM, Chandni R, Varma S, Pandiar D (2017) Analysis of lip print and fingerprint patterns in patients with type II diabetes mellitus. J Oral Maxillofac Pathol 21(2):309-315 https://doi.org/ 10.4103/jomfp.JOMFP_17_16

Prabhu RV, Dinkar AD, Prabhu VD (2010) Collection of lip prints as forensic evidence at the crime scene-an insight. J Oral Heal Res (Internet) 1(4):129-135 https://wwwresearchgatenet/publication/259372733 Accessed (May 2021)

Ragab AR, El-Dakroory SAEA, Rahman RHA (2013) Characteristic patterns of lip prints in Egyptian population sample at Dakahlia governorate. Int J Legal Med 127(2):521-527 https://doi.org/10.1007/s00414-012-0784-5

Rastogi P, Parida A (2012) Lip prints-an aid in identification. Aust J Forensic Sci 44(2):109-116 https://doi.org/10.1080/00450618.2011.610819

Renaud M (1973) L'identification che'iloscopique en médecine légale. Editions Médicales et Universitaires Google scholar Accessed (May 2021)

Santos M (1967) Queiloscopy: a supplementary stomatological means of identification. Int microform J leg med 2. Google scholar accessed may 2021

Sekharan CP (2011) LIP FORENSICS- forensic Cheiloscopy for crime investigation and criminal identification. Anand Publications, Bangalore

Sivapathasundharam B, Prakash PA, Sivakumar G (2001) Lip prints (cheiloscopy). Indian J Dent Res 12(4):234-237 https://europepmcorg/article/ med/11987663 Accessed (May 2021)

Suzuki K, Tsuchihashi Y (1970) Personal identification by means of lip prints. J forensic med 17(2):52-57. Google scholar accessed may 2021

Suzuki K, Tsuchihashi Y (1971) A new attempt of personal identification by means of lip print. J Can Soc Forensic Sci 4(4):154-158 https://doi.org/10. 1080/00085030.1971.10757287

Tsuchihashi Y (1974) Studies on personal identification by means of lip prints. Forensic Sci 3(3):233-248 https://doi.org/10.1016/0300-9432(74)90034-X

Webb LG, Egan SE, Turbett GR (2001) Recovery of DNA for forensic analysis from lip cosmetics. J Forensic Sci 46(6):1474-1479 https://doi.org/10. 1520/JFS15174J

\section{Publisher's Note}

Springer Nature remains neutral with regard to jurisdictional claims in published maps and institutional affiliations.

\section{Submit your manuscript to a SpringerOpen ${ }^{\circ}$ journal and benefit from:}

- Convenient online submission

- Rigorous peer review

- Open access: articles freely available online

- High visibility within the field

- Retaining the copyright to your article

Submit your next manuscript at $\boldsymbol{\nabla}$ springeropen.com 